\title{
Treatment of advanced thyroid cancer refractory to therapy
}

\author{
Barbara Jarząb \\ From 4th Congress of the Polish Thyroid Association 2013 \\ Lodz, Poland. 11-13 April 2013
}

Radioiodine treatment constitutes the most effective therapeutic option of advanced differentiated thyroid cancer. Unfortunately, about $30 \%$ cancers do not show radioiodine uptake or do not respond to therapy.

Thyrosine kinase inhibitors (TKI), among them axitinib, cabozantinib, lenvatinib, motesanib, pazopanib, sorafenib, sunitynib and vandetanib, constitute a new group of drugs implemented to therapy of both differentiated thyroid cancer (DTC) and medullary thyroid cancer (MTC). They inhibit growth factor receptors which play crucial role in processes of growth, differentiation and maturation of neoplastic cell. Detailed information related to mechanism of action of each drug as well as to conducted clinical trials are given in the table below:

Until now the only registered drug in advanced MTC is vandetanib. Its efficacy has been proved in phase III study. Significant prolongation of progression free survival (PFS) was observed for patients receiving vandetanib compared

Table 1

\begin{tabular}{|c|c|c|c|}
\hline Drug name & Mechanism of action & $\begin{array}{l}\text { Clinical trials } \\
\text { (phase) }\end{array}$ & Indications \\
\hline MOTESANIB & $\begin{array}{l}\text { VEGFR1,2,3, PDGFR, } \\
\text { c-KIT, RET }\end{array}$ & $\|$ & MTC, DTC \\
\hline SORAFENIB & B-RAF, VEGFR1, VEGFR2 & $\|/\| \|$ & MTC \\
\hline AXITINIB & VEGFR, c-KIT, PDGFR-B & $\|$ & DTC \\
\hline SUNITINIB & $\begin{array}{l}\text { VEGFR1, 2, PDGFR, } \\
\text { c-KIT, FLT3, RET }\end{array}$ & ॥ & DTC \\
\hline LENVATINIB & VEGFR1,2,3, FGFR1 PDGFR & $\|/\| \|$ & MTC \\
\hline CABOZANTINIB & MET, VEGFR2, RET & III & DTC \\
\hline PAZOPANIB & VEGFR, PDGFR, c-KIT & $\|$ & MTC \\
\hline VANDETANIB & RET, VEGFR, VEGFR2, EGFR & $\|$ & DTC \\
\hline
\end{tabular}

with placebo group (30.5 months vs. 19 months, respectively). Published results of phase II studies have preliminarily proved the efficacy of axitinib, sorafenib and sunitinib in DTC (beneficial therapeutic effects of partial regression or disease stabilization was noticed in $68 \%, 76 \%$ and $75 \%$ cases, respectively). The highest response rate (partial regression) was obtained in DTC patients treated with pazopanib (49\%). Whereas, in phase II clinical trials with cabozantynib, motesanib and sorafenib carried out in MTC, disease control was achieved in 90\%, $83 \%$ and $94 \%$ patients, respectively.

The most common side effects are skin reactions such as photosensitivity, rash, hand-food syndrome, arterial hypertension, gastrointestinal - diarrhea, nausea, vomiting, stomatitis and decrease in body weight. Majority of them have slight or moderate intensiveness (G1 and G2 according to Common Terminology Criteria for Adverse Events). The tolerability of TKI is acceptable and does not affect the quality of life.

Published: 5 April 2013

doi:10.1186/1756-6614-6-S2-A22

Cite this article as: Jarząb: Treatment of advanced thyroid cancer refractory to therapy. Thyroid Research 2013 6(Suppl 2):A22. 